\title{
ANALYSIS OF IMPACT OF WIND ON PHOTOVOLTAIC PANELS
}

\author{
Karol Tucki, Anna Baczyk, Mateusz Zimoch \\ Warsaw University of Life Sciences, Poland \\ karol_tucki@sggw.pl
}

\begin{abstract}
The aim of the paper was to perform computer analysis of the influence of turbulent flow $k-\mathcal{E}$ on photovoltaic arrays in two different types of extreme conditions. The first analysis was based on the assumption that the flow goes from the front to the rear plane, while in the second one, the opposite underlying assumption was used. In light of the rapidly developing energy sector, marked by the prevalence of solar power plants and changes in wind turbulence, both planned and in-progress technological projects need a thorough simulation and analysis. The information obtained expands our knowledge on the impact of wind on solar power systems and makes it possible for us to proceed to further stages of work and optimise the solutions implemented. Both analyses were performed in the Comsol Multiphysics application, which is a modelling and numerical platform software dedicated for this type of solutions. Moreover, a 3D model of PV panels was examined in CAD environment, with the use of Autocad. Research clearly shows that the biggest impact of wind on PV modules is observed, when the wind blows from the rear plane towards the front plane. The immediate cause of the above is the declination of the panels with respect to the Earth's surface, which, in the present analysis, was $30^{\circ}$. When the declination is decreasing, both yields and the impact of the wind on the surface of the modules are decreasing too and the cover of subsequent rows of the installation is reduced. Our results confirm the need to apply the recommended angles of solar panels. Therefore, it is particularly important that additional analysis (analysis of turbulent wind flow and stop-wind projects) should be performed while developing photovoltaic farms. To minimise the effect of the wind, future studies should focus mainly on the improvement of positioning the modules, their height and spread as well as the right choice of the place.
\end{abstract}

Keywords: photovoltaic panel, turbulent flow k-E, CFD module, Comsol Multiphysics, Autocad.

\section{Introduction}

In accordance with the national renewable energy action plans and the European Union deeds [1], Poland is obligated to sustainably increase to at least $15 \%$ the renewable energy source contribution in the gross final consumption of energy by 2020 , taking into account a number of aspects such as supplies generated from renewable energy sources, raw materials used in the production of fuels and conditions of the power system [2]. Electrical power is one of the most universal and versatile types of energy, with photovoltaics being a standard and the most environmentally-friendly of all tools used to obtain renewable energy from solar radiation [3]. Power generation by solar cell systems does not cause emission of pollutants to the natural environment, landscape degradation, interference with the functioning of flora and fauna or noise [4-5].

Photovoltaic installations (PV) are becoming an increasingly popular element of the Polish landscape. Polish experience connected with the preparation of investments and investigation of already existing ones leads to the conclusion that the technical expertise of investors and fitters of such systems is still insufficient [6]. This, in turn, causes differences between the planned and the final costs of investments, extended duration of works, losses in the process of obtaining solar energy and safety of facilities. To minimise the consequences mentioned above, dedicated actions are implemented, permitting the application of optimum solutions at all stages, from the selection of support structures and module placement angles to the analysis of the impact of atmospheric conditions on the solar system [7-8].

The aim of the study is to perform a simulation of turbulent wind flow $k-\varepsilon$ on photovoltaic panels for the most and the least favourable wind conditions. The simulation shall be carried out with the use of COMSOL software after modelling the installation in AUTOCAD.

\section{Material and methods}

The subject of the study is the analysis of the impact of wind on photovoltaic modules in extreme boundary conditions. To perform the analysis, we needed two independent research facilities, in which we could carry our experimentation in the form of impact simulation. As the first facility, we used photovoltaic panels with a support structure and fixing devices. The second one, in turn, was a boxshape wind solid with the appropriate inlet, outlet, flow turbulence and velocity parameters. 
The study encompassed the following issues: (1) selection of photovoltaic panels and structural elements of the PV systems, (2) development of a 3D model of the solar plant in AUTOCAD, (3) transfer of the CAD project to COMSOL, (4) creation of a $k-\varepsilon$ turbulent air flow box-shaped solid, including: (a) specification of characteristic dimensions of the box-shaped solid, (b) localisation of photovoltaic modules in space, (c) assuming the wind in- and outflow direction for the two cases analysed, (d) establishment of symmetrical conditions, (e) development of computational networks, (5) predetermination of wind parameters for the simulation, (6) calculation of wind distribution, pressure and speed in COMSOL and (7) CFD simulations of wind inflow onto the photovoltaic panels.

The work was performed with the use of Autocad and Comsol Multiphysics software, i.e. two leading tools for computer-aided drafting in both two and three dimensions. The tools are mutually compatible in the designs produced, owing to which models created with the use of one of them can be analysed using the other, and vice versa. The $k-\varepsilon$ model is the most widely used model during tests of turbulent flows. The model was implemented directly to Comsol Multiphysics.

\section{Results and Discussion}

The first of the parameters presented herein is the distribution of wind velocity within a designated area of a box-shape solid, calculated for two cases.

The turbulent wind acting on panels has a significant impact on the surface of such panels, which immediately shows the disturbances of the flow and velocity, if any. Initially, the disturbance reached c.a. $20 \mathrm{~m} \cdot \mathrm{s}^{-1}$ (Fig. 1). Together with the growth of the height (in the upper plane), the anomaly lengthways of the photovoltaic panels decreased and so did the velocity of wind streams spreading sideways. This is due to the bigger stability of the flow and fluid adjustment to the specific element after the first critical contact therewith in the lower area.

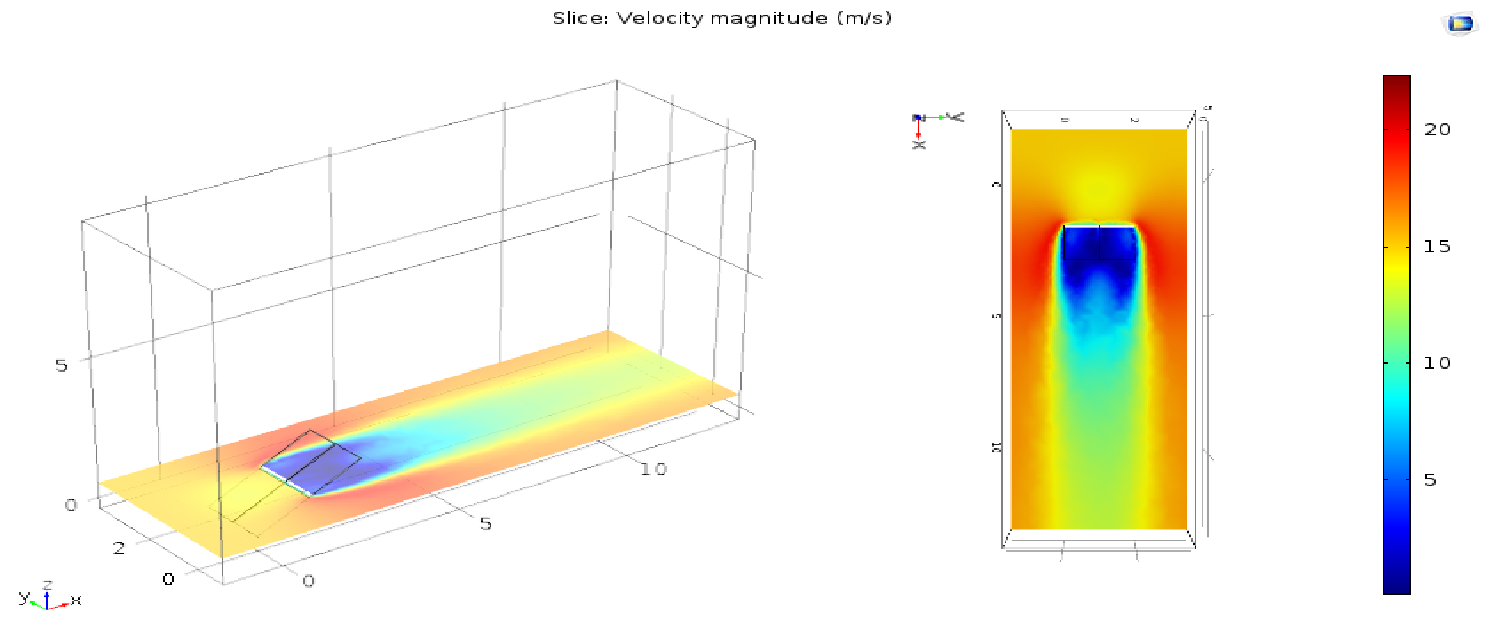

Fig. 1. Wind velocity distribution along XY axis - mid-plane of photovoltaic model - case 1

To confront the above-presented data for flow conditions from the front to the rear plane, case 2 was also analysed, representing an opposite approach. Here, the flow disturbance was bigger, while velocity distribution was smaller (max. up to $20 \mathrm{~m} \cdot \mathrm{s}^{-1}$ ) (Fig. 2), which was caused by orientation of the panels with reference to the inflowing medium. When inclined "upwind", the modules stopped the wind and absorbed its energy, while in case 1, they made a "propelling springboard".

The second of the parameters analysed in the CFD simulation (also for two research cases) was the distribution and changes of pressure across the surface of the photovoltaic panels.

The highest pressure values and the biggest differentiation thereof were observed at the site of the first contact of panels with turbulent wind, i.e. in the lower part. As altitude grows, the values stabilise and decrease. This is due to changes in the wind velocity as presented on the model. At the site where velocity is the lowest, the pressure is the highest and the other way round (Fig. 3). The other side of the model, except for the lower areas, is characterised by minor pressure diversity and very low wind velocities. The reason for the above is absence of significant flow variations, as the majority of the medium is transported across the surface of the modules. Nevertheless, as the air flows in the lower 
part, too, accumulation of isolines is observed close to the ground, indicating very high diversity of wind directions and velocities in the area. The area is characterised by the presence of wind vortexes, the parameters of which are variable and irregular by definition.

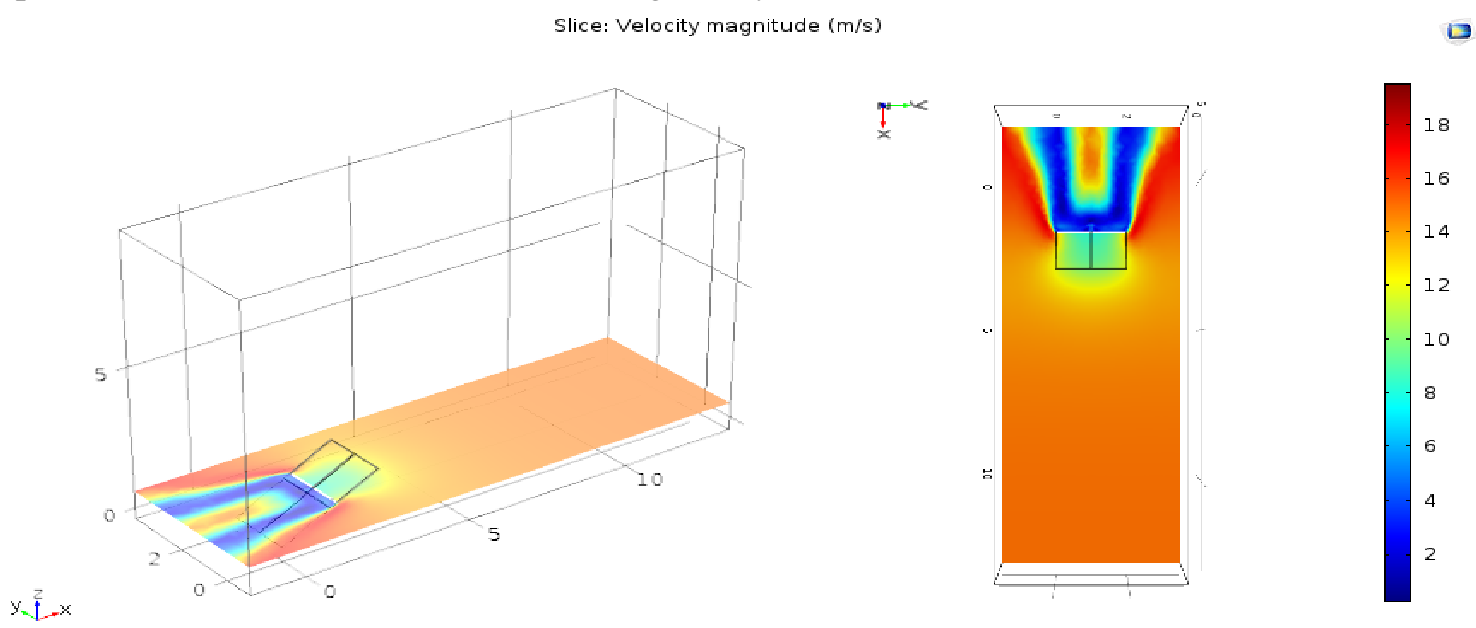

Fig. 2. Wind velocity distribution along XY axis - mid-plane of photovoltaic model - case 2

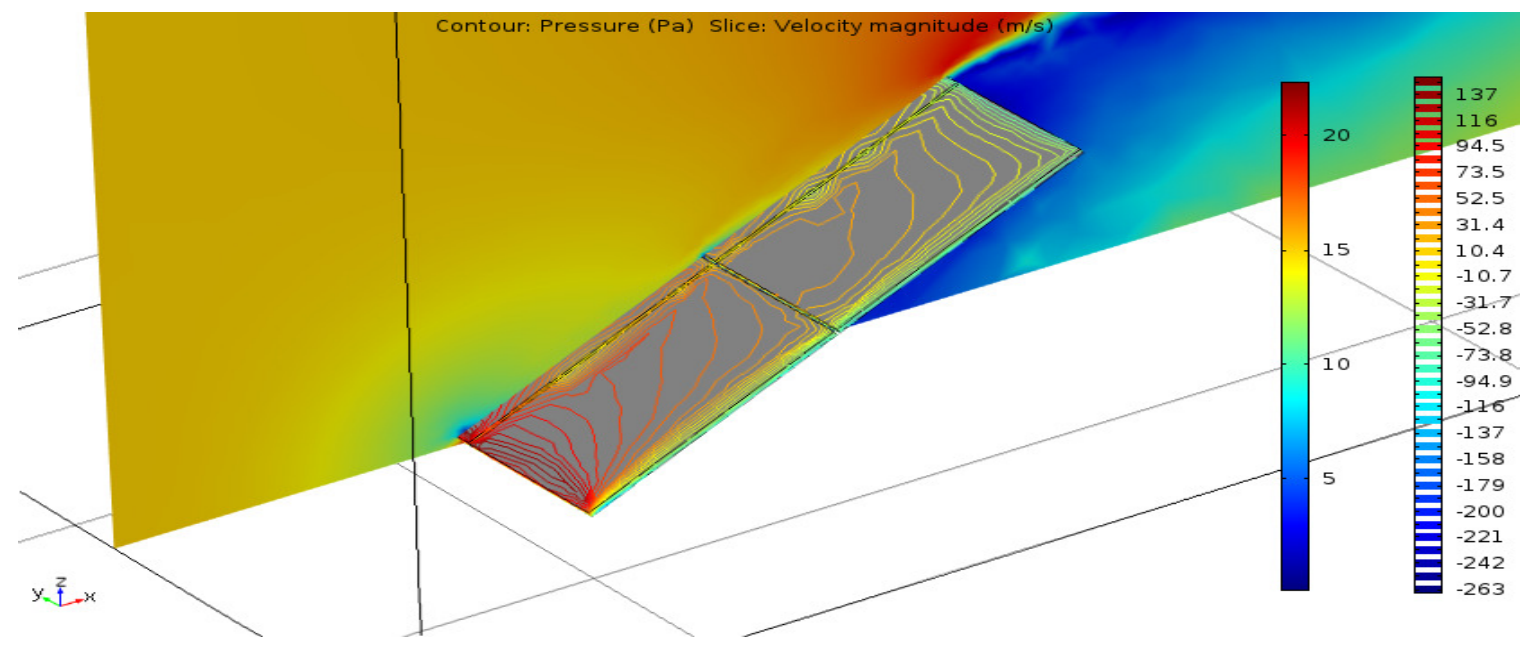

Fig. 3. Wind pressure and velocity - case 1

The next stage consisted of deliberations and visualisation of simulations for case 2 (Fig. 4) In this case, the values are higher but their range is lower than in case 1. As a result, higher stresses occur, with bigger impact on the structure of panels. Additionally, the pressures alongside the model remain at a similar level and do not decrease so quickly together with the decrease of the height as where the air flows in from the opposite side. Here, the load on the system, although high, is distributed evenly, which further confirms our conclusions concerning the impact of panel orientation on the retention of energy and the velocity of wind. The other side of the model, in turn, represents a low-pressure zone, where the distribution of pressure is constant and non-variable. When compared to case 1, the values are lower and more evenly distributed, as the majority of impact is transferred onto the surface that immediately receives the wind pressure [9-10]. The only correlation is observed in the zone on top of the area analysed, where the presence of vortexes leads to accumulation of different pressures and velocities and the consequent plotting of a large number of isolines.

It must be noted that the values shown represent anomalies of differences between pressures occurring on the surface of a PV system, and not absolute values of pressures present at the site delineated by the isoline. By choosing this type of presentation, we wanted to show immediate changes that occur under wind pressure.

The parameters of impact of wind turbulences $k-\varepsilon$ on the photovoltaic modules for both cases are the isosurfaces of propagation of air mass velocity of $15 \mathrm{~m} \cdot \mathrm{s}^{-1}$ and the wind vortexes produced. Deliberations concerning these indicators have been presented in 3D. 
In case 1 it was found that medium of the specified value presses against the modules only in its central part. Underneath, the air velocity is bigger, while above the value is much lower (Fig. 5).

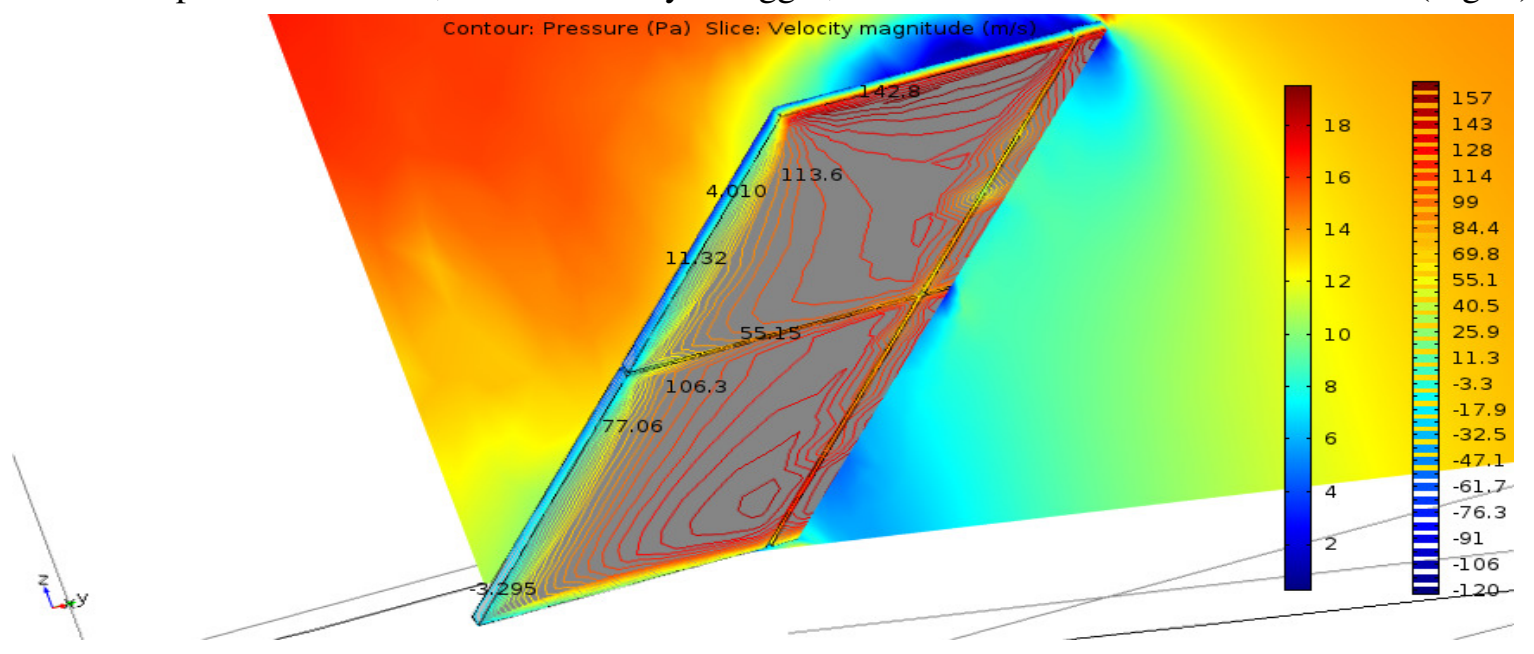

Fig. 4. Wind pressure and velocity - case 2
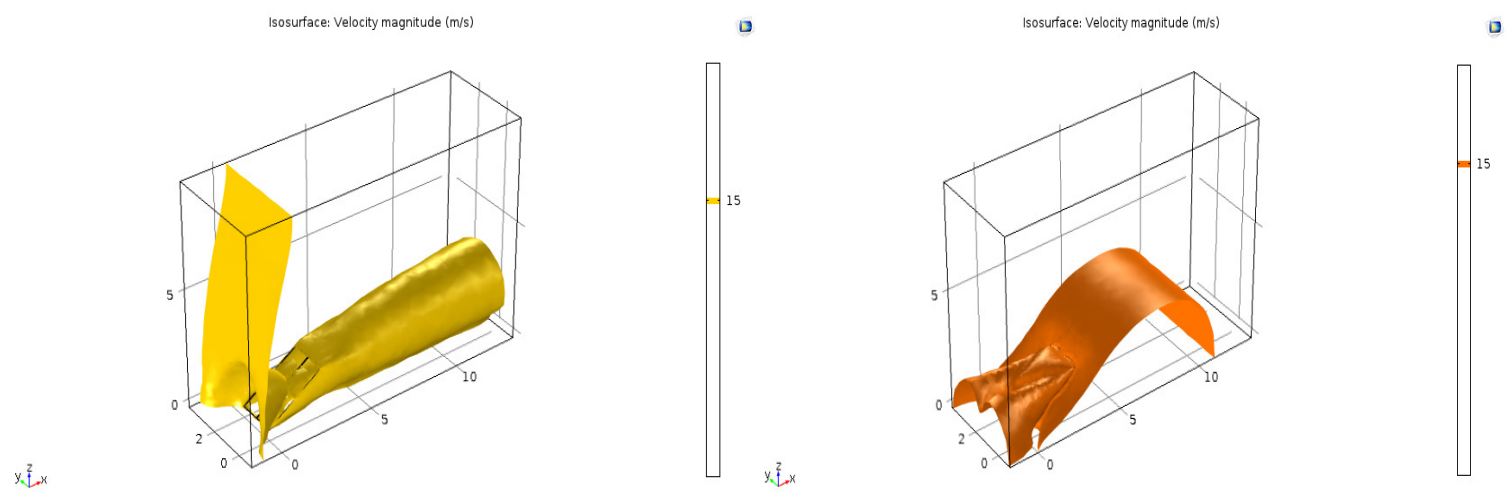

Fig. 5. Wind velocity isosurface for $15 \mathrm{~m} \cdot \mathrm{s}^{-1}-$ cases 1 and 2

In case 2, in turn, the target velocity of the wind stream acts on the panels only in the upper zone, which is positioned upwind. Additionally, the so-produced isosurfaces show the creation of a partition that affects the fluid flow in adjacent zones. As shown in both cases, this produces tunnels of diversified velocities, which can be significant given the plans to install further rows of photovoltaic facilities and, therefore, should be subjected to more detailed testing.

Finally, the simulation also encompassed visualisation of wind vortexes. To start with, it must be noted that the visualisation was focused on disturbances in flow streams and only indirectly refers to the impact of vortexes on the photovoltaic modules. In both cases, 30 wind streams acting on the area of immediate contact with the wind were analysed, and their behaviour both on and outside of the model was verified. The solution made it possible for us to carry out a final comprehensive assessment of the problem analysed and complements the simulation of the impact of fluid turbulences on the model designed.

From the rear panel perspective, the vortexes take up the width of c.a. $2.5 \mathrm{~m}$ and have a turbulent, irregular structure (Fig. 6). The impact zone of the turbulences covers the entire research area. Additionally, the turbulences depict the sideways spread of the streams from the moment they flow in and come into contact with the modules until they have freely flown around them [4].

In case 2 (Fig. 7), in turn, the vortexes presented cover the area of $4.5 \mathrm{~m}$. What is worth noting that they occur separately, which is typical of flows divided/separated by obstacles on their way. At the same time, the wind streams are hauled inwards, towards the Earth, which explains bigger accumulation of energy, increased and steady pressure and wind stopping, as a result of which the wind velocities within the areas located further on are much lower. 

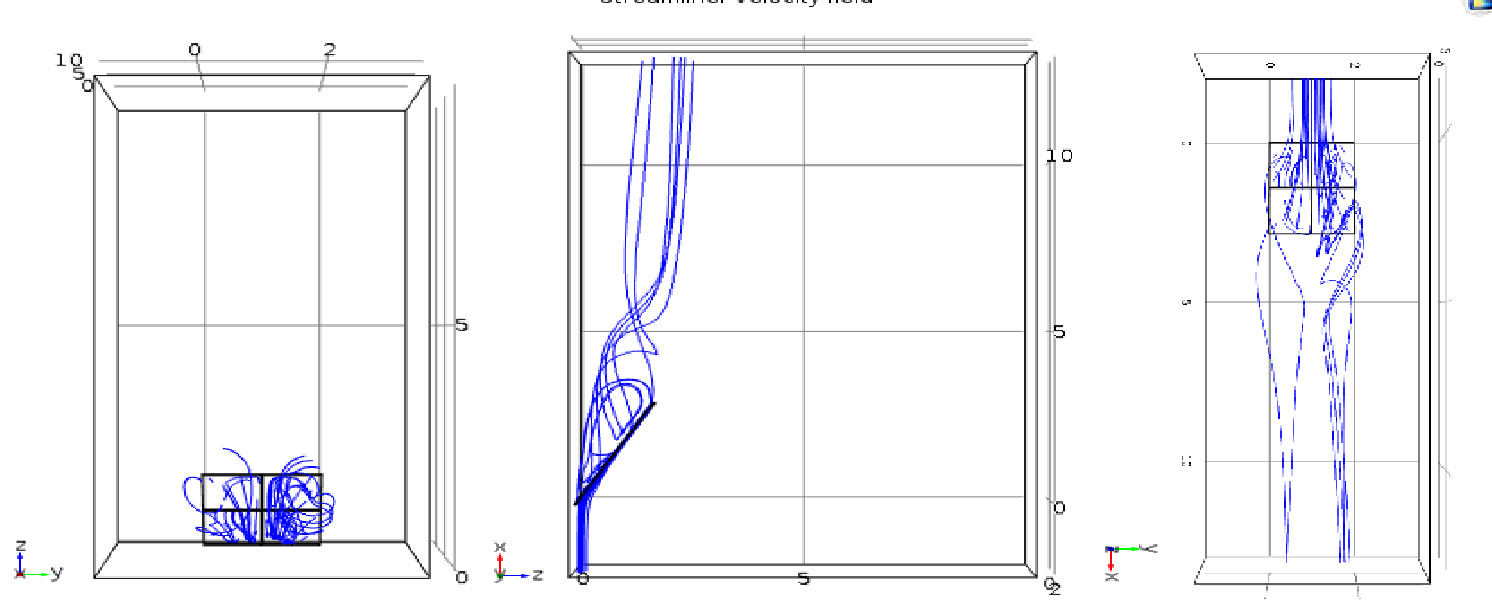

Fig. 6. Wind vortexes - case 1

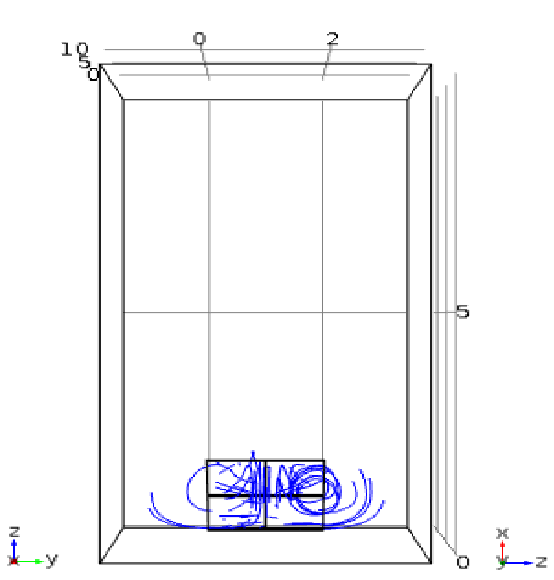

Streamline: Velocity field
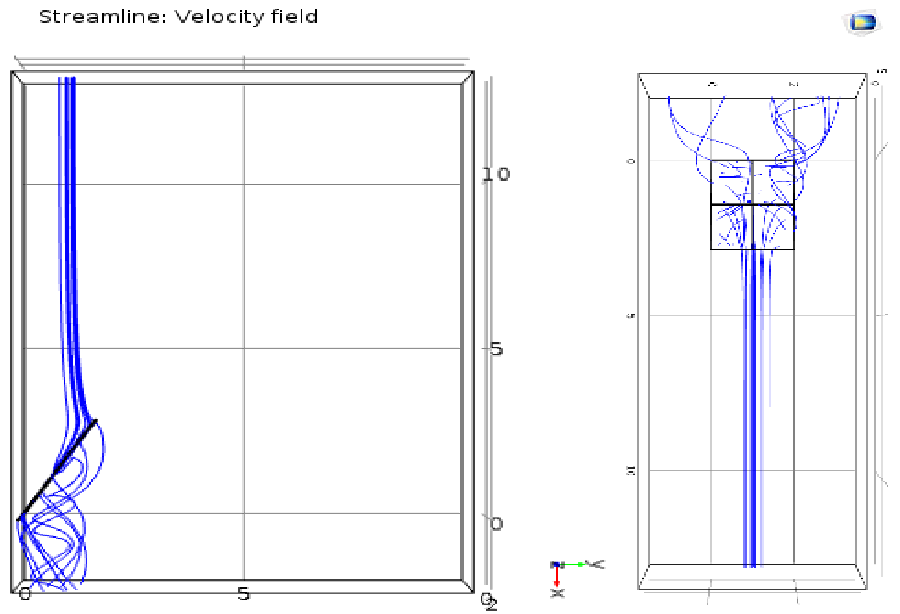

Fig. 7. Wind vortexes - case 2

\section{Conclusions}

1. The present article concerns the impact of $k-\varepsilon$ wind turbulences on photovoltaic panel arrays in open and enclosed space, for two research cases, i.e. for wind advection:

- from the front plane towards the rear plane,

- from the rear plane towards the front plane.

2. Given the fast development of the power sector, the commonness of the use of solar power plants and changes in wind turbulences, both planned and in-progress technological projects need a thorough simulation and analysis. Only then shall we learn the impact of wind on the installation and, consequently, be able to optimise the solutions implemented.

3. The conclusions presented above show beyond any doubt that the biggest impact of wind on photovoltaic modules is observed for wind advection from the rear plane towards the front plane (case 2). The immediate cause of the above is the declination of the panels with respect to the Earth's surface, which, in the present analysis, equalled $30^{\circ}$.

4. In light of the current scientific opinion, this very value of the declination is considered best in the face of optimisation of electricity production as part of the investment. As the declination decreases, the impact of wind on the surface of modules drops, too, leading to decline of the yields and weaker protection of subsequent rows of the installation. Together with growth of the wedge parameter the pressure and volume of the air mass stopped grows, which immediately translates into the necessity to reinforce the support structures.

5. All of the afore-quoted arguments force constructors to position photovoltaic panels at recommended angles and to perform additional analyses of the wind flow and stoppage for the 
most favourable and critical conditions, when executing projects for the construction of photovoltaic farms. To minimise the wind impact, further studies in the field are needed, aimed at improvement and distribution of modules, their downsizing and reduction of span as well as the proper selection of installation site, which, if characterised by weak wind velocity distribution, eliminates the problem.

\section{References}

[1] Directive 2009/28/EC of the European Parliament and of the Council of 23 April 2009 on the promotion of the use of energy from renewable sources and amending and subsequently repealing Directives 2001/77/EC and 2003/30/EC. [online] [22.04.2018]. Available at: https://eurlex.europa.eu/legal-content/EN/TXT/?uri=celex:32009L0028

[2] Trela M., Dubel A. Comparing the support systems for renewable energy sources in Poland green certificates vs auction systems. Energy Policy Journal, Vol. 20 (2), 2017, pp. 105-116.

[3] Wan C., Zhao J., Song J., Xu Z., Lin J., Hu Z. Photovoltaic and solar power forecasting for smart grid energy management. CSEE Journal of Power and Energy Systems, Vol. 1 (4), 2015, pp. 3846.

[4] Matuszczyk P., Popławski T., Flasza J. Analysis of various types PV modules under real atmospheric conditions, Przegląd Elektrotechniczny (Electrical Review), Vol. 93 (1), 2017, pp. $169-172$.

[5] Marcewicz T., Partyka J., Mazur M. Elektrownie fotowoltaiczne w Polsce - rozwiązania techniczne na przykładzie istniejących obiektów (Photovoltaic power plants in Poland - technical solution, analysis of energy production based on existing facilities). Przegląd Elektrotechniczny (Electrical Review), 92 (8), 2016, pp. 151-154. [online] [22.04.2018]. Available at: http://pe.org.pl/articles/2016/8/41.pdf (In Polish)

[6] Piliński M. Instalacje fotowoltaiczne na budynkach mieszkalnych. Uwarunkowania techniczne budowy. (Photovoltaic installations on residential buildings. Technical conditions of construction), Warunki Techniczne.PL (Technical Conditions.PL), No 1 (12), 2016, pp. 39-43. [online] [22.04.2018]. Available at: http://magazyn.warunkitechniczne.pl/spis-tresci-numeru/12 (In Polish)

[7] Samadhiya A., Pandey R. Analysis of PV panels under various weather conditions. International Journal of Emerging Research in Management and Technology, Vol. 5(2), 2016, pp. 53-61.

[8] Guo B., Javed W., Figgis B.W., Mirza T. Effect of dust and weather conditions on photovoltaic performance in Doha, Qatar. First Workshop on Smart Grid and Renewable Energy (SGRE), Doha, Qatar. 2015 First Workshop on. [online] [22.04.2018]. Available at: https://ieeexplore.ieee.org/document/7208718/

[9] Puneeth Kumar H.P., Dr. S. B. Prakash: CFD analysis of wind pressure over solar panels at different orientations of placement, International Journal of Advanced Technology in Engineering and Science, Vol. 2 (07), July 2014, pp 313-320. [online] [22.04.2018]. Available at: http://ijates.com/images/short_pdf/1406577220_P313-320.pdf

[10] Uslu V. Computational fluid dynamic analysis of wind load acting on ground monuted solar panel (master thesis). 2014, pp. 49-83. [online] [22.04.2018]. Available at: http://etd.lib.metu.edu.tr/upload/12617682/index.pdf 